\title{
Transition factors analysis of human settlement
}

\author{
S.-T. Kuo \& Ch.-J. Chen \\ Graduate Institute of Urban Development and Architecture, \\ National University of Kaohsiung, Taiwan
}

\begin{abstract}
A settlement is an historical domain that consists of its constitution and the regulations of development. Under the influence of natural, economical and social conditions, the structure, as well as its function as a human settlement, is thus unceasingly changing. The space development of human settlements in Taiwan went along with the different policies from the Japanese occupation period to the republican era. The primitive human settlements are gradually brought into the entirety of the national development. However, the settlements became subsequently unvaried without their own identity when the authority imposed the rigid policies of development with uniform thinking.

In fact, the change of the space of human settlements always reflects the different influencing factors when facing immigration, location, and development. This study focuses on what are the critical influencing factors of the transition of human settlements. The further purpose is to propose and to establish an appropriate model for developing or for revitalizing the settlements. Some new visions and viewpoints are also presented through the analysis of documentation where the different events and transition processes are described.

Besides, this study uses the theory of Man-Land Relationship to observe the circumstance and the transition of the human settlement. The weight of influencing factors is thus classified and is compared after analyzing and inducing the various causes and consequences. The results of this study are finally expected to be applied on the further discussion of models for urban planning and settlement development.
\end{abstract}

Keywords: human settlement, transition factors, development models, identity.

\section{Introduction}

Due to the National Land-Use Plan and conventional policy, it is obvious that the aboriginal settlements are usually over-exploited related to the environmental 
conditions. However, the development of these settlements is falling behind compared to the Han's settlements.

By means of a filed survey, the over-exploitation of the settlement provokes not only the shortage of natural resources, but also leads to socio-economic problems. In the past, although many aboriginal communities obeyed the national policy to "improve" their own infrastructure and spatial conditions, the essential change of the settlements was never consciously accepted by themselves.

This study undertakes the different approaches such as documentation analysis, field survey and inductive method basing on different theories of spatial and environmental planning. Moreover, one most important tribe in southern Taiwan-Paiwan, including two settlements, are chosen as examples for the case study. This research focuses not only on the issues of aboriginal people, but also in trying to develop a comprehensive methodology and model to analyse the development of aboriginal settlements.

The goal of this study on the one hand is to review the process of transition for each settlement and to analyse the causes and results of transition. On the other hand, it is to develop an analytical model considering various influencing factors alone on the history of settlement. Figure 1 show the concept schema of the research [1].

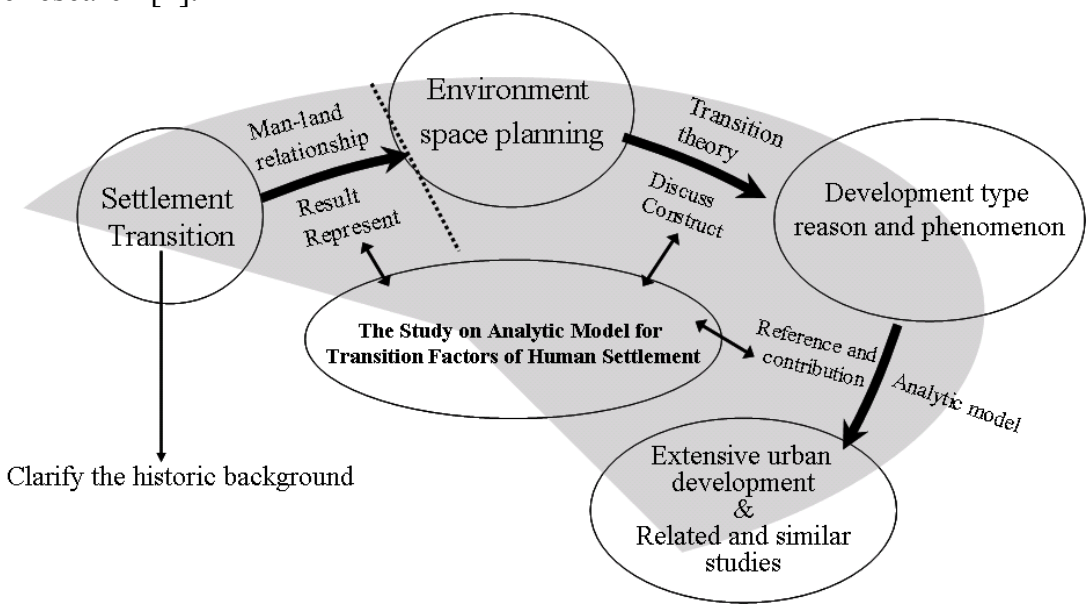

Figure 1: $\quad$ Schema of the study.

\section{The development and transition of settlement}

\subsection{General distribution of aboriginal tribes in Taiwan}

There are actually more than 490,000 indigenous people in Taiwan, about $2 \%$ of the total population. Totally, 14 tribes have been officially recognized. Each with their own distinct language, cultural features, traditional customs and social structure, which represent the most precious historical and cultural resources of Taiwan. Figure 2 shows the distribution of the aboriginal tribes in Taiwan from 1895 to 1945 [2]. 


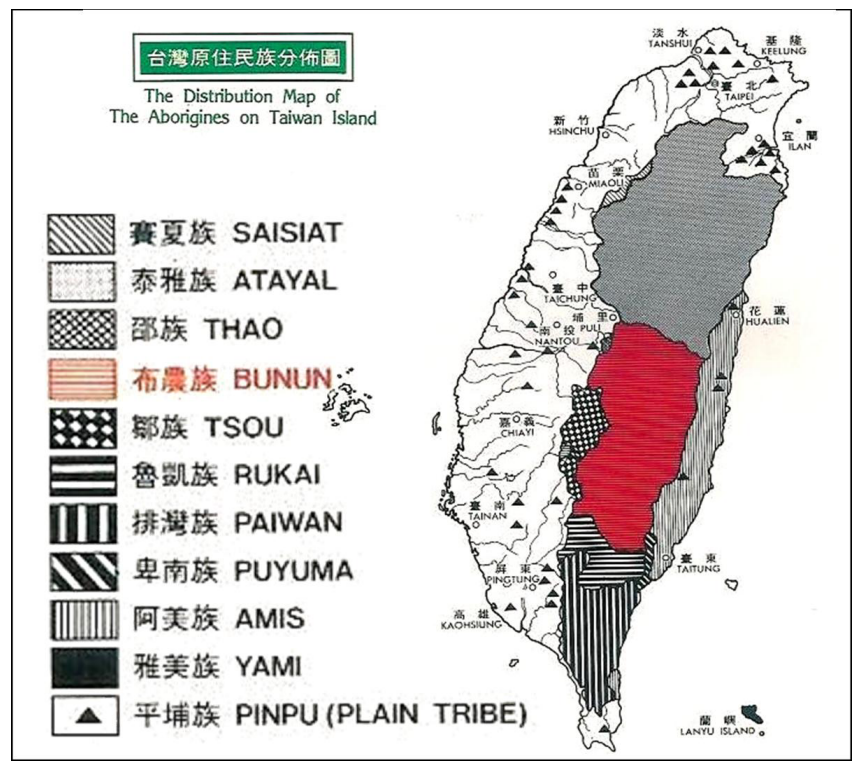

Figure 2: $\quad$ Aboriginal tribes in Taiwan during Japanese colonial period [3].

The classification of aboriginal people started in the Japanese colonial period. Inou Kanori is one of the first scholars who advocated this. The actual classification method used by Taiwanese government was established by Tsuchida.

\subsection{Analyse of transition of settlements}

Taiwan's modern history goes back about 400 years, along the different historic periods (before the Ching dynasty, Japanese colonisation, and after World War II), various causes such as natural disasters, land-production, tribal disputes, alien colonisation and type of governance implicated the transition of the settlements and involved with different levels and intensities during different periods.

After reviewing different periods, we observe that the main causes which influence the settlements are natural disasters, land-production and tribal disputes before the Japanese colonial period (before 1895). The alien colonisation and type of governance become more influencing during Japanese Colonisation (1895-1945) and after World War II (after 1945) (see Figure 3).

\section{Analyse on factors of settlement transition}

\subsection{Variety of factors and its content}

It is necessary to clarify the hierarchy of the above complex causes for analysing the transition of a settlement. In accordance with documentation analysis and 


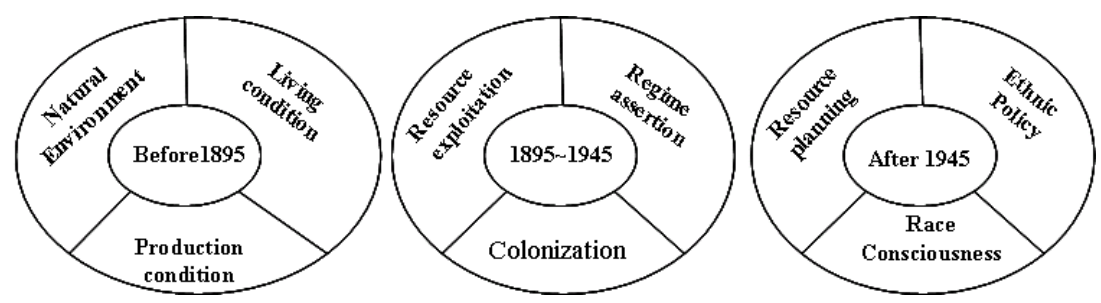

Figure 3: Influencing causes in different periods.

case studies, we can classify all causes into two groups, each group behaves as one "Axial Factor", they are: Environmental and Spatial Factor (ESF) and Political and Economic Factor (PEF).

The content of the Environmental and Spatial Factors consist of natural conditions (disaster), living condition (land and space), productive condition (cultivated and hunting lands), and tribal disputes. The Political and Economic Factors can be divided into two sub-axis as Social-Cultural Factors (SCF) and Human-Historic Factors (HHF). The Social-Cultural Factors include tribal system, community organisation, custom and ceremony. The Human-Historic Factors involve language, history, consciousness and spirit.

According to the documental analysis, it is evident that the Political and Economic Factors were usually the most influencing factors, which induced the transition of the settlements because it is hard to resist the economic enticement and authority of the government as well. Figure 4 expresses the system of these factors.

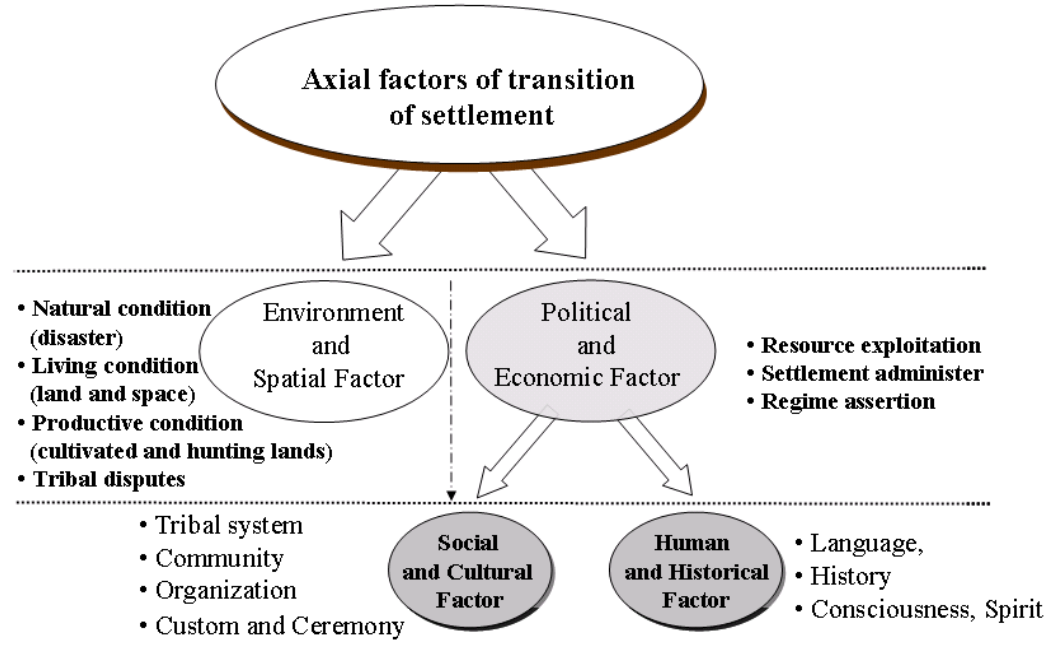

Figure 4: $\quad$ System of influencing factors. 


\subsection{Case study}

In order to apply and to testify the above factors' structure, this study takes two settlements of Paiwan tribe as the case study. Paiwan tribe, close to 86,000 in population, is the biggest tribe in southern Taiwan, the third largest aboriginal tribe in Taiwan. The Paiwan tribe has its authentic settlement types and housing system as well. All building structures are constructed with numerous slats of stone and are built at the same altitude on mountains, merging with the landscape. This type of vernacular architecture represents strongly, affordable resources and a kind of natural attitude that responds well with the environmental conditions. Using the local materials, applying the natural cooling and the landscape adaptation, and forming the self-sufficient community, the Paiwan habitat behaves as an eco-habitat and reflects subtropical characteristic of Southern Taiwan.

Kaviyangan and Chukadan; two settlements are selected because of their representativeness and importance for the Paiwan people. By analysing the historic development and different status in different periods, it is provable that the above factors effectively implicated the transition of settlements (Figure 5).

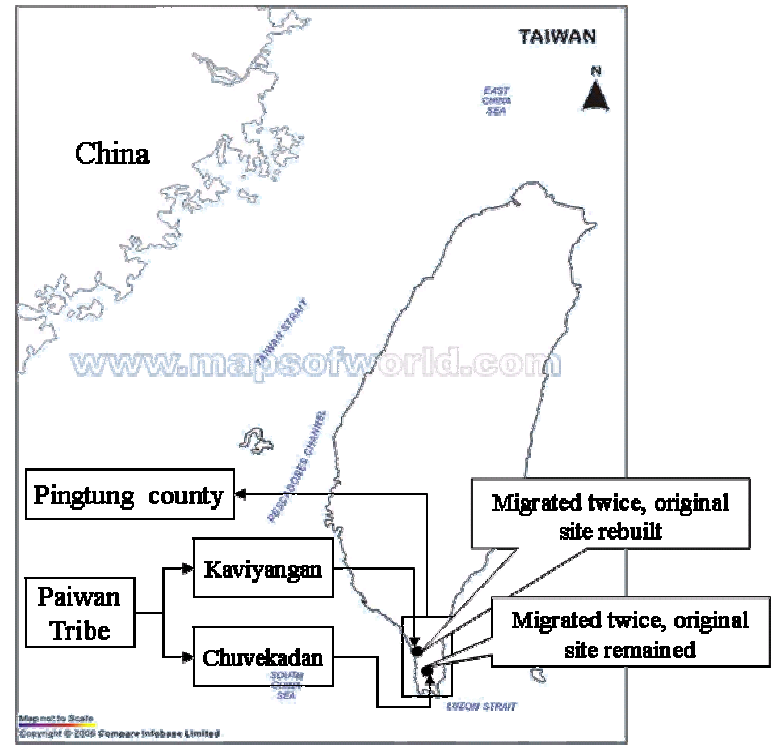

Figure 5: Description of case study.

Kaviyagan is one of the most important settlements of Paiwan Tribe. It used to be designated as a cultural heritage during Japanese colonial period. Nowadays it remains as ethnic and cultural symbol for Paiwan people (see Figure 6) [4]. Chuvekadan is another settlement of Paiwan that remains intact due to its tardy development. Consequently it possesses numerous traditional dwellings and original landscape. Figure 7 shows a general view of settlement. 


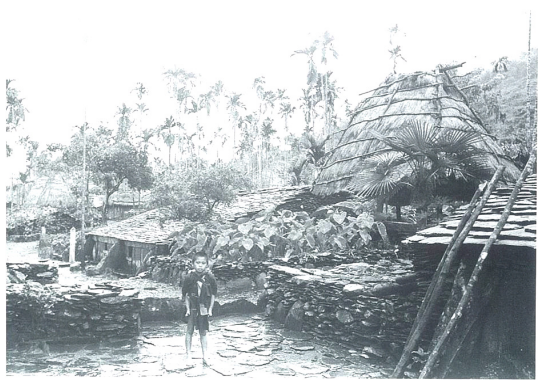

Figure 6: Traditional settlement of Kaviyangan before 1945 (left).

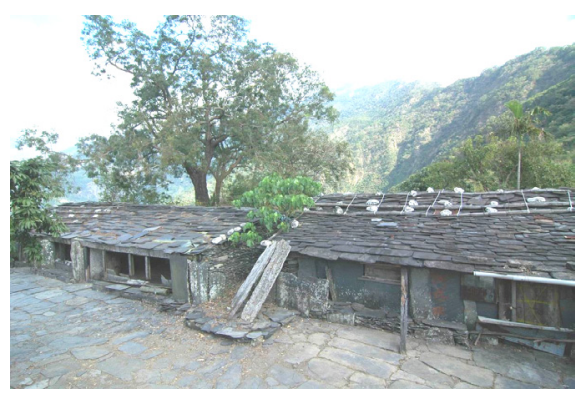

Figure 7: Traditional chief house of Chuvekadan (right).

\subsubsection{Kaviyangan settlement}

Different factors act on the settlement of Kaviyangan as primary and secondary factors in Figure 8. Figure 9 explains different factors in four periods. Figure 11

\begin{tabular}{|c|c|c|c|c|}
\hline $\begin{array}{l}\text { Periods } \\
\text { Factors }\end{array}$ & $\begin{array}{c}\text { Before } \\
1895 \\
\end{array}$ & $1895 \sim 1945$ & $\begin{array}{l}\text { After } \\
1945 \\
\end{array}$ & \\
\hline ESF & $\bullet$ & ๑ & & \multirow{4}{*}{$\begin{array}{l}\bullet: \text { Primary factor } \\
\odot \text { : Secondary factor }\end{array}$} \\
\hline PEF & & $\bullet$ & $\bullet$ & \\
\hline $\mathrm{SCF}$ & & & $\odot$ & \\
\hline $\mathrm{HHF}$ & & & ๑ & \\
\hline
\end{tabular}

Figure 8: $\quad$ Primary and secondary factors.

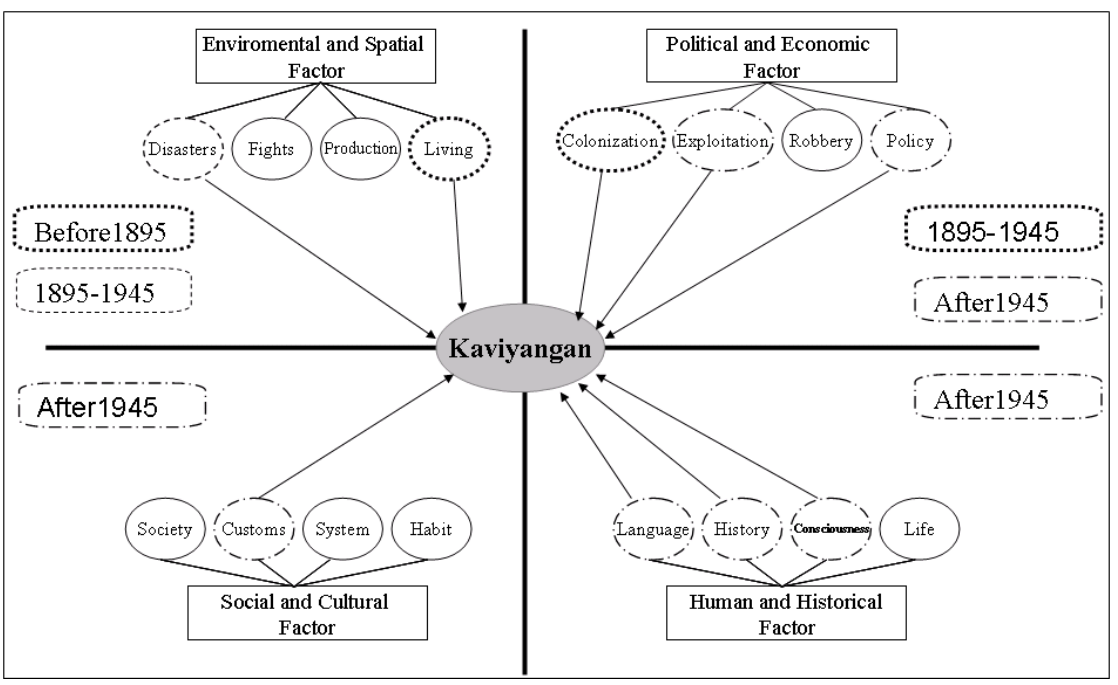

Figure 9: Different factors in four periods. 


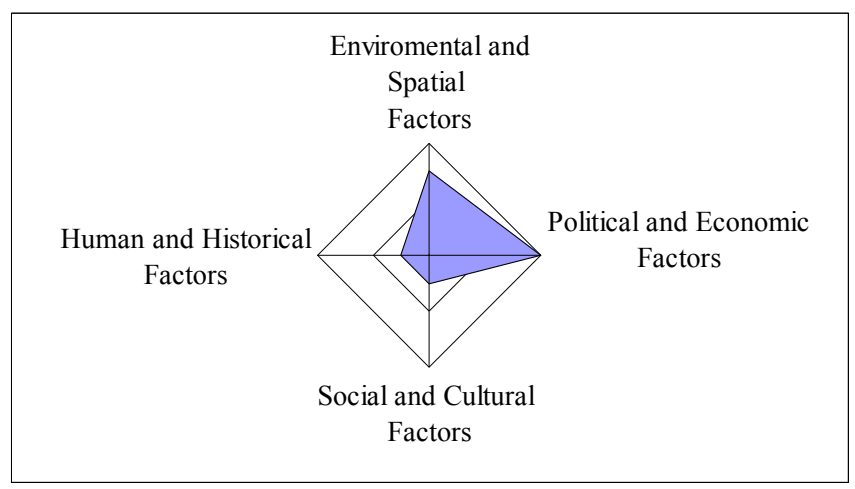

Figure 10: Influencing intensity of different factors.

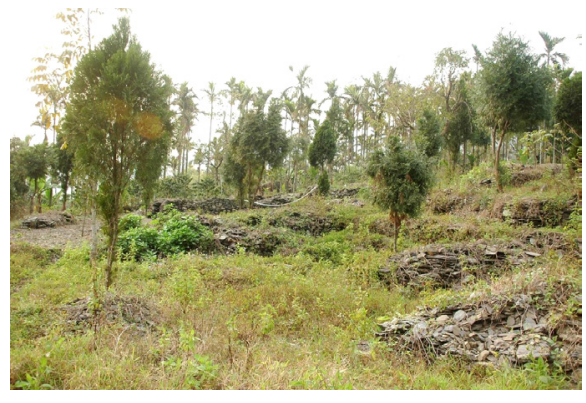

Figure 11: $\quad$ Original site.

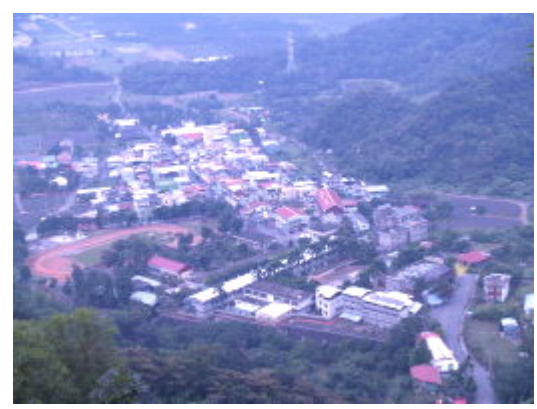

Figure 12: New settlement.

is the influencing intensity of factors. The environmental and spatial factors such as natural disasters urged the migration of Kaviyagan before 1895 and during the Japanese colonial period (1895-1945). The political and economic factors intervened during Japanese colonial period and after World War II (after 1945). Finally, the social-cultural factors and the human-historic factors stepped in the development of settlement after 1945 until now, accompanying with the selfawareness of the tribe. The mother language, history and the traditional customs are gradually reconsidered and emphasised.

Figure 11 shows the original site of Kaviyangan, once the largest settlement in the region, only the ruins of the village can be recognised today. Figure 12 is the new community situated below the old site, displayed as a modern township but without distinguishing character.

\subsubsection{Chuvekadan}

Different factors act on the settlement of Chuvekadan as primary and secondary factors in Figure 13. Figure 14 explains different factors in four periods.

The environmental and spatial factors, such as natural disasters, twice encouraged migrations of Chuvekadan after 1945. The political and economic factors obviously intervened only after World War II (after 1945). Same as the 
case in Kaviyangan, recently the social-cultural factors and the human-historic factors strongly influence its development. The settlement is stimulated by more cultural and ecological activities, such as conservation of cultural property and eco-tourism. The issues on reviving the tribe and cultural reconstruction are more and more discussed and reflected [5].

\begin{tabular}{|c|c|c|c|c|}
\hline $\begin{array}{l}\text { Periods } \\
\text { Factors }\end{array}$ & $\begin{array}{c}\text { Before } \\
1895\end{array}$ & 1895-1945 & $\begin{array}{l}\text { After } \\
1945\end{array}$ & \\
\hline ESF & $\bullet$ & $\bullet$ & $\bullet$ & \multirow{4}{*}{$\begin{array}{l}\bullet: \text { Main factor } \\
\odot \text { : Secondary factor }\end{array}$} \\
\hline PEF & & & $\bullet$ & \\
\hline $\mathrm{SCF}$ & & & ๑ & \\
\hline $\mathrm{HHF}$ & & & ๑ & \\
\hline
\end{tabular}

Figure 13: Main and secondary factors.

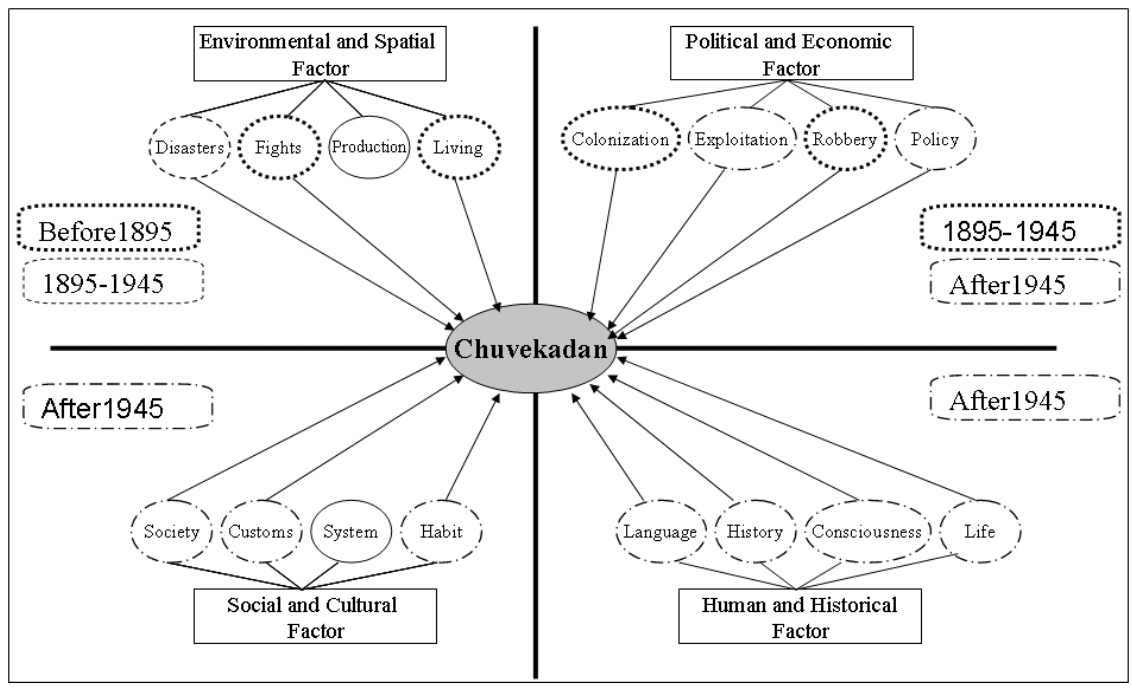

Figure 14: Different factors in four periods.

The main differences of the above two settlements are that not only the political and economic factors implicated in different timing, but also the type of governance leads to a different manner of exploitation on resources and their spatial appearance. Figure 15 explains the influencing intensity of factors.

Figure 16 shows the original site of Chuvekatan where the original landscape is conserved as well as the living aspect without massive reconstruction. Figure 17 shows a modified traditional dwelling which manifests a vigorous local development. 


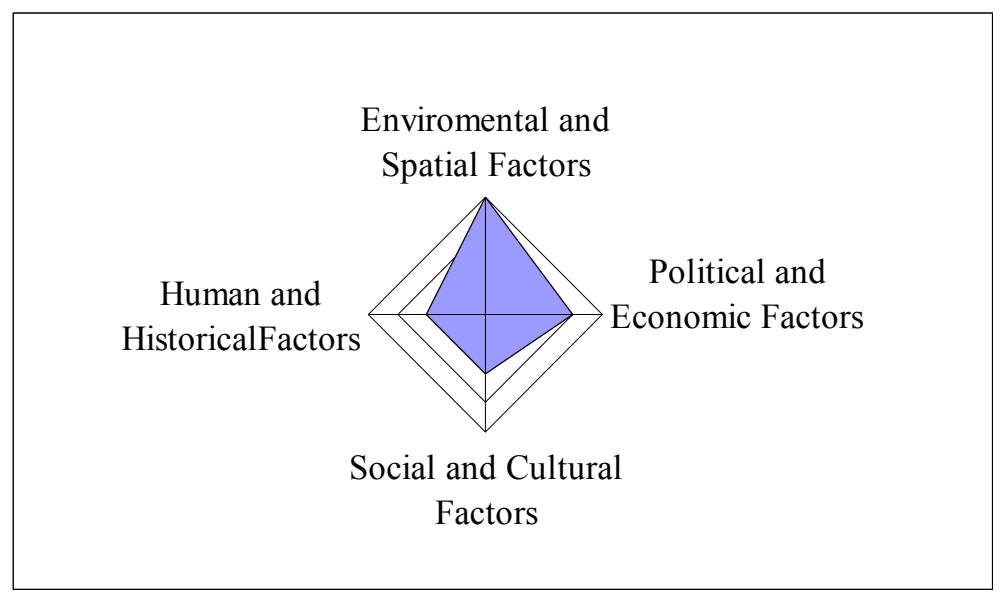

Figure 15: Influencing intensity of different factors.

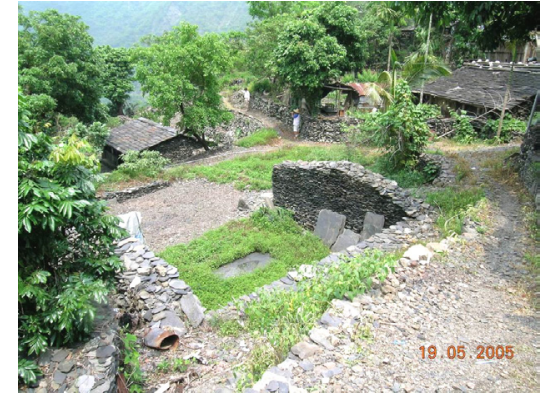

Figure 16: Original site.

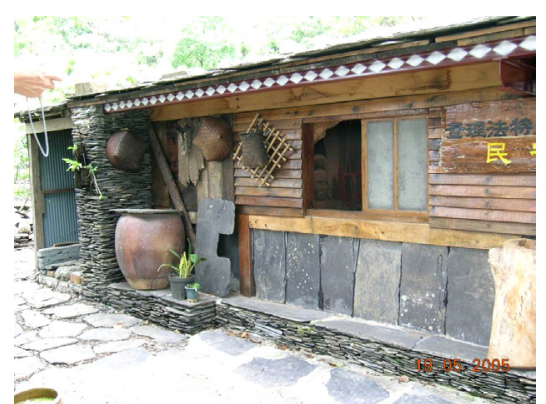

Figure 17: $\quad$ Modified dwelling.

\section{Conclusion}

The results of the case study show: even two settlements belonging to an identical tribe-Paiwan, the process as well as the consequences of transition of settlement shows them to be dissimilar. This reveals the conspicuous influence of the factors that are discussed in the study.

The conventional visions on human settlement without taking care of the history and the identity of human settlement itself will lead to the mediocre planning models lacking of its own characteristics and essence. The sustainability of human settlements should be built based on this identity concluding traditional culture, history and social singularity.

The concrete outcomes of this study are listed as following:

(1) Different effects caused by different influencing factors for human settlement in time axis are described and analysed. 
(2) Instead of conventional perception, an analytical model is proposed for the further discussion of urban planning and settlement development.

(3) Two real cases are analysed as empirical evidences using proposed analytical model.

\section{References}

[1] Kuo, S.-T., (2009), "The Study on Analytic Model for Transition Factors of Human Settlement", Master Thesis of Graduate Institute of Urban Development and Architecture, National University of Kaohsiung, TAIWAN

[2] http://www.apc.gov.tw/main/index_en.jsp

[3] http://www.tta.gov.tw/ch/chinese

[4] Kasahara, Seiji (1999), "The Image of Aborigine in Taiwan - Photo set by Prof. Asai, Erin", SMC Publishing Inc.

[5] C. J. CHEN (2006), "The study of restoring an eco-habitat of the traditional Paiwan tribe in Taiwan", Eco-Architecture: Harmonisation between Architecture and Nature, pp.73-82, WIT Press 